\title{
Article
}

\section{Calendar as a Criterion in the Study of Culture}

\author{
Marija Šegan-Radonjić ${ }^{1, \ddagger}$ and Stevo Šegan ${ }^{2, \ddagger}$ \\ 1 Mathematical Institute of the Serbian Academy of Sciences and Arts \\ 2 Department of Mathematics, State University of Novi Pazar
}

\begin{abstract}
The paper considers the calendar as a link between the cosmos and mankind, and it introduces it as an instrument in studying culture. It uses the concept of calendars/calendar systems as a criterion for recognition and formation of culture in general. Starting from an assumption that the calendar is a structurally organized system of events or holidays, it analyses the basic units of a calendar: day, month and year, and distinguishes a calendar holiday from a non-calendar holiday. It states that the calendars are a structural list of collective memory within a social group, where this memory is described in cyclical categories - calendar holidays. Furthermore, considering that the initial epoch of year counting may be different in different cultures, it discusses how cultural self-awareness is expressed through the epoch of the calendar era. Finally, it explores how and to what extent the formation, interaction, and reforms of calendars and their systems reflect the change in culture. The paper concludes that calendars and their systems should be used as a criterion in defining culture.
\end{abstract}

Keywords: Calendar; Culture.

\section{Introduction}

Culture, as a notion, can be considered in a narrower and a broader sense ${ }^{1}$, and some theoreticians have succeeded to identify as many as 164 definitions of this phenomenon [2]. Furthermore, modern science strives to comprehend and describe this phenomenon as generally as possible, and the new complex disciplines, such as the problem of culture typology (criterion) [3], have appeared and been developed. In the following text, we aim to answer the following research question: could a calendar be used as a criterion in the study of culture?

If culture is regarded or approached as "that complex whole which includes knowledge, belief, art, morals, law, custom, and any other capabilities and habits acquired by man as a member of society" [4], then a calendar could be regarded as a criterion of culture. It is known or used by every member of a specific society; it is (most frequently) time-invariable for hundreds of years and used continuously; and it reflects concepts of time, which is its most important function in a cosmological model system of second-order.

In the scientific literature, there are a few examples where a calendar is determined as a criterion of culture. For instance, a German-Mexican anthropologist, Paul Kirchhoff used ceremonial activities and calendar as "cultural trait" determining the space of Mesoamerica [5]. Also, an American anthropologist, Alfred L. Kroeber, accepted "permutating ritual calendar" as a suitable criterion for determining the region of the high culture of Mesoamerica [6]. Finally, in research on Akan culture, the Akan calendar is selected as criteria for recognition and formation of culture [7] [8].

1 More on methodological concepts of culture, see Fischer, 2007 [1] 
Above mentioned studies usually focus on a specific calendar as a criterion for defining a specific culture. In this paper, however, we will try to avoid the too general, as well as too specific definitions of culture by connecting the natural (astronomical) and social (cultural) cosmologies, where the category of time appears as an unavoidable argument and function. We use the concept of calendars/calendar systems as a criterion for recognition and formation of culture in general. Starting from an assumption that the calendar is a structurally organized system of events or holidays, we analyse the basic units of a calendar: day, month and year, and distinguish a calendar holiday from a non-calendar holiday. We find that the calendars are a structural list of collective memory within a social group, where this memory is described in cyclical categories - calendar holidays. Furthermore, considering that the initial epoch of year counting may be different in different cultures, we discuss how cultural self-awareness is expressed through the epoch of the calendar era. Finally, we explore how and to what extent the formation, interaction and reforms of calendars and their systems reflect the change in culture. We conclude that calendars and their systems should be used as a criterion in defining culture.

The rest of the paper is organized in the following way. In §2, we analyse the calendar as a structurally organized set of collective memory within human societies. In $\S 3$, we explore the connection between the calendar era and cultural self-awareness. We then analyse some aspects of cultural interaction and shift by comparing the selected calendars and their systems in $\S 4$ and $\S 5$. $§ 6$ concludes with suggestions for future research.

\section{Culture as Collective Memory Manifested in the Calendar}

The nominal and direct function of a calendar is to describe the position in time of a phenomenon, or an event. Assuming that experience (culture!) about regular repetitiveness of the phenomenon and its duration do exist, a day (based on the duration of Earth rotation $h$ ), a month (based on the lunation) and a year (based on the duration of Earth's revolution around the Sun) are adopted as the basic units of a calendar.

Every calendar recognizes the day as the smallest calendar unit of time and represents a system for organizing the smallest units of time to reckon the longer time intervals. However, regardless of the smallest, general unit, the various methods have been used in creating calendars, and currently, there are more than 40 different calendars in use [9]. For example, some of them are replicas of astronomical cycles following permanent rules (e.g., Julian or Gregorian calendars), others are based on abstract continuous cycles that have no astronomical meaning (e.g., Olympiad dating).

If a day is accepted as the smallest calendar unit, then it includes both repetitive and non-repetitive features. Repetitive features include, for example, the position of a day within a year (e.g., Wednesday, 20th day in a month, etc.) or a year as the summary statement of the number of days (e.g., common year, leap year, year of the snake, etc.). The non-repetitive characteristic of a day arises from a fact that a day is an ordinal number of the year as a time interval from a starting point - the epoch of reading (e.g., the historical event of the assassination of Archduke Franz Ferdinand, which happened on June 15, 1914, on the Julian calendar (Figure 3) or June 28, 1914, on the Gregorian calendar (Figure 2)). Therefore, it is inferred that two conceptions of time exist in every calendar: the linear and the cyclical one.

As for the cyclical conception of time, the year in the existing calendars reflects natural phenomena, mostly the cyclicity of the seasons. It should be noted, however, that the reflection of a natural phenomenon in a calendar often becomes a metaphysical phenomenon. For example, the "Inundation of the Nile," a holiday which was introduced in Egypt because of the real flooding of the Nile River, at some point stopped to correspond to the real event. That, however, did not prevent its celebration [12]. Also, the proclaimed (conventional) cyclicity of the International Astronomical Union 


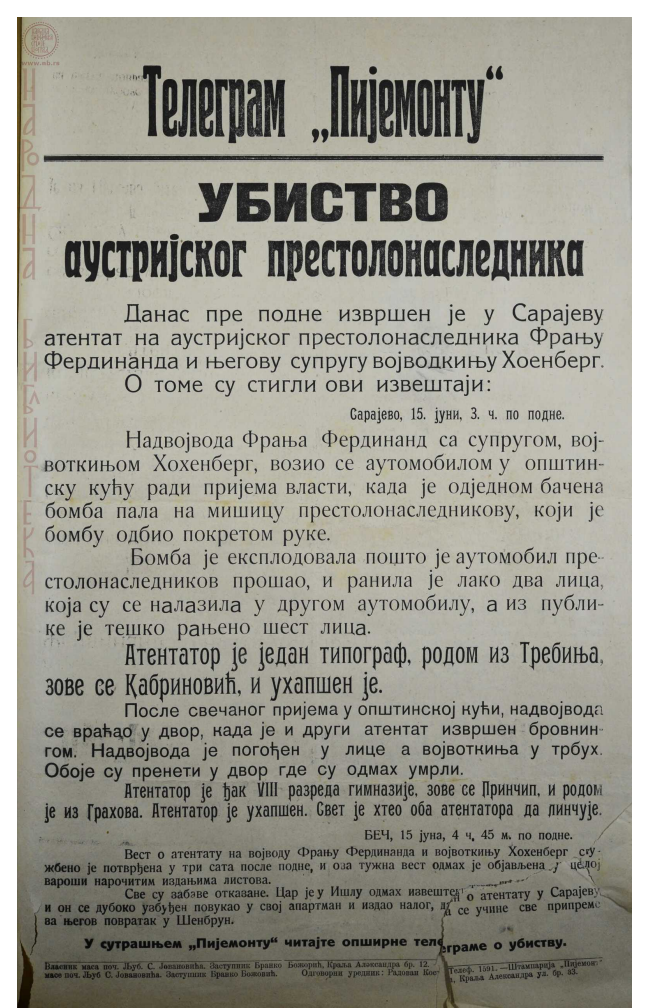

Figure 1. The historical event of the assassination of Archduke Franz Ferdinand reported in the Serbian newspaper, which used Julian calendar (Collection of the University Library "Svetozar Markovic") [10].

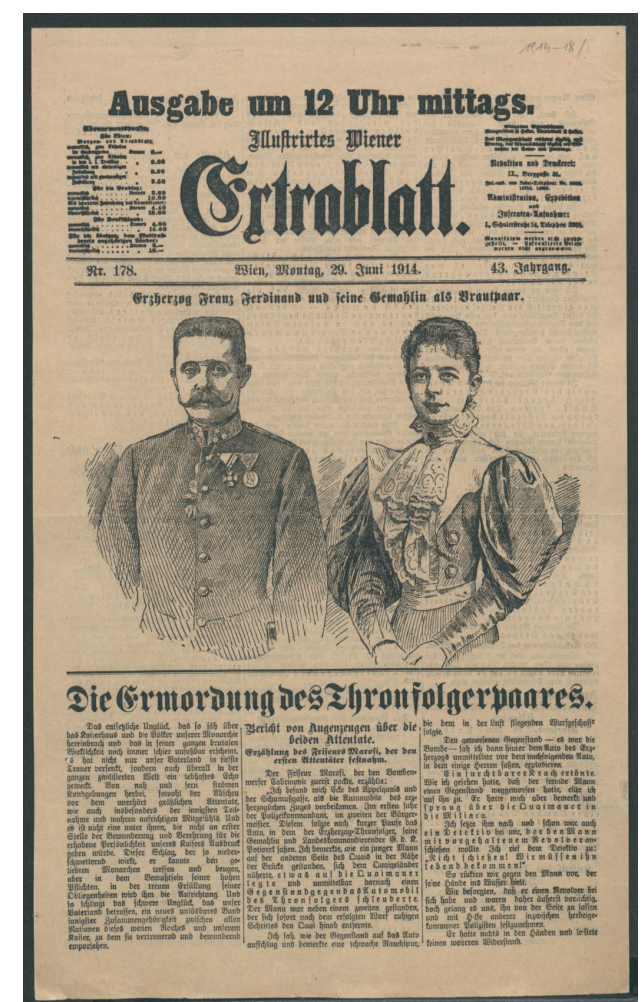

Figure 2. The historical event of the assassination of Archduke Franz Ferdinand reported in the Austrian newspaper, which used Gregorian calendar (Collection of the National Library of Austria) [11]. 


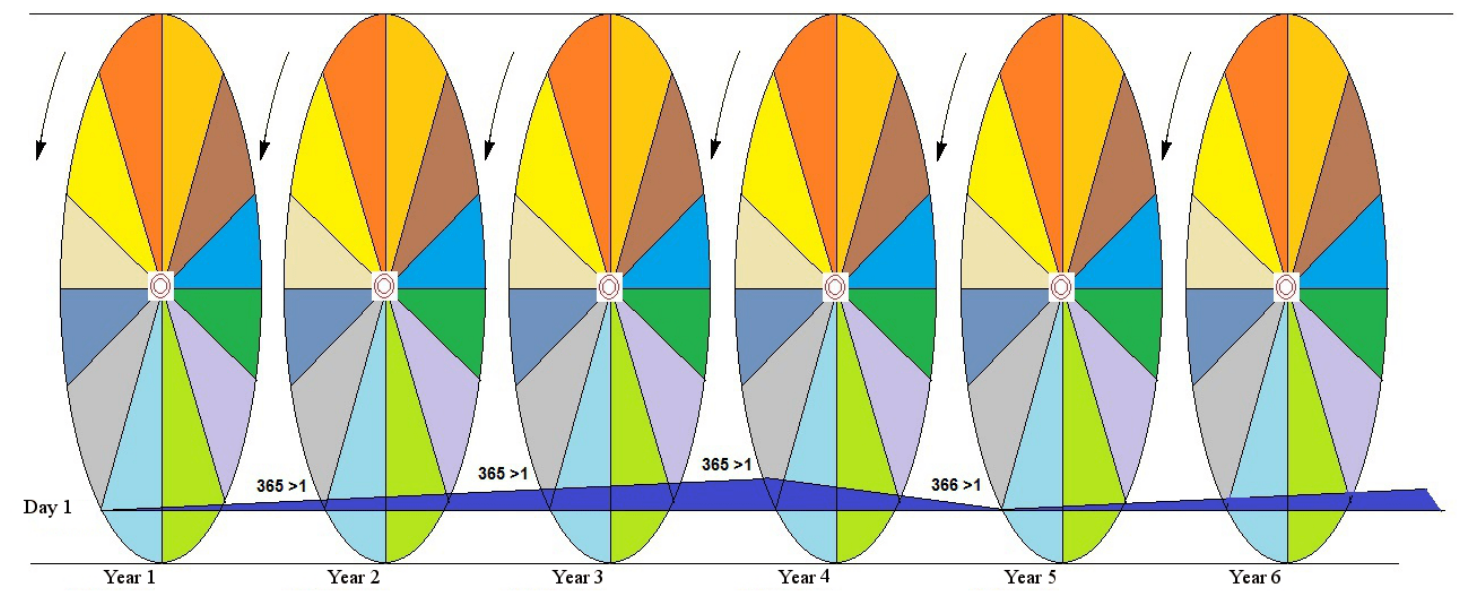

Figure 3. Graphical interpretation of the occurrence of a leap year in the four-year cycle.

General Assembly do not follow any natural cycle; the year divided into months do not follow the seasons either, weeks do not follow the lunar phases, etc. What is, then, a calendar year in such a context?

Ancient Romans used the word "fasti" for the calendar, meaning holidays (festivals) [13] whereas in most of the European languages there is also a word "almanac" for the calendar, which is said to emanate from the Coptic word "almenichiaká, i.e. astrological charts containing a list of lords of the ascendant [14]. Therefore, the calendar could be seen as a non-repetitive and finite sequence of holidays/events/phenomena, the duration of which is approximately equal to that of a finite sequence of year seasons.

If the calendar is accepted as a sequence of holidays or events, then it is important to distinguish a calendar holiday from a non-calendar holiday. A calendar holiday contains a ritual repetition of an event from mythology or real history and is, therefore, characterized by a linear repetitiveness in the framework of the annual cycle. It may be celebrated on the same calendar day (e.g., the ancient Roman holiday "Saturnalia" celebrated on December 17 in honor of the Roman god Saturn or the French National Day, "Bastille Day", celebrated on July 14), but not necessarily (e.g., the Jewish holiday "Passover", a commemoration of the Jewish people leaving Egypt, which takes place in spring, on Saturday, on the 15th day of Nissan month or Christian holiday "Easter", whereby the resurrection of Jesus is celebrated, taking place in spring as well). Thus through a calendar holiday, some mythological and historical facts of a social community are reproduced and celebrated, and the corresponding réglementation is established in their sacralized form.

A non-calendar holiday is a holiday which, though not included in the official calendar of a social community, is an important part of the memory of the members of that community, for instance, celebrations of birthdays, wedding anniversaries, joining armed forces, etc.

Therefore, the set of events or calendar holidays does determine the cultural norms within a community. It is a structural set of collective memory within a social group, where this memory is described in cyclical categories - calendar holidays. When included in the calendar system, a calendar is presumed to be complete both in the cyclical and linear senses. A proper analysis could show that only complete calendar systems can be good criteria in the study of culture. 


\section{Cultural Self-Awareness and Calendar}

Year counting in a calendar (calendar system), unlike the annual cycle, is not universal. It obeys the linear conception of time and yields the time interval from a calendar origin - the epoch of the calendar era - which is not the same in all cultures. For example, in the Byzantine calendar, years are counted from the creation of the world [15], in the Islamic world from Hijrah, the emigration of Prophet Mohammed from Mecca to Medina [16], in the Zoroastrian calendar from the reform of Sassanid Emperor Ardashir I [17]. The initial epoch is a historical product and it belongs to a civilized society ${ }^{2}$. If the culture is manifested as a collective memory in the cyclical calendar, then the origin of a calendar is a form of cultural self-awareness.

In early societies, there is usually a collection of narratives, myths about the creation, about the common ancestor, totem animal, etc. [19]. The narrators may, but need not, be contemporaries of the event which is the subject of their narration. It is difficult to relate such an event to any general historical perspective; it can be chronologically determined only by following the principle of then/now. The self-awareness of contemporaneity as a culture result, which had been born at a given time to pass afterwards a strictly determined time path, is already characteristic of civilization. The initial epoch is not a description of culture in the way of listing the events forming the structure (cyclical calendar); but it is rather a culture's self-determination, which reflects the collective consciousness about the basic condition for the sustainability of the culture. The initial epoch indicates the unity of culture, regardless of all its modifications, as long as previously chosen time reckoning is valid.

The counting of eponymous years from a person's coming to power (e.g., Chinese dating according to the ruling years of their emperors - niánhào [20] or Roman consular dating [21]), as well as interval counting (for instance, ancient Greek dating according to Olympiad [22])) in no way denies the role of the initial epoch. On the contrary, it confirms this role; the characteristic of the year is additionally related to one of the conditions of the sustainability of a society.

Accordingly, cultural self-awareness is expressed through the initial epoch of year counting and may differ among societies. To accept the initial epoch of a different culture bearers means to introduce their self-awareness. This is a quality that makes such activity usually rejected and undesirable. In this context, a calendar era is non-objective beyond its own culture and non-convincing to the other cultures.

\section{Acculturation and Calendar}

Culture presents a dynamic social category that changes through history due to the different circumstances. A cultural change known as "acculturation," is a process when two or more cultures of different social groups come into mutual contact and influence one another [23]. There are several types of possible mutual cultural contacts [23], and in this section, we will briefly analyse some aspects of cultural interaction claimed to be universal, such as rejection, co-existence, modification and acceptance, resistance and conflict [24] by comparing the selected calendars. It should be noted that, in the following text, the calendars are regarded as collective memory bearers for different social groups (see §2).

An interesting case of cultural interaction is the suppression and rejection of the pagan culture of the Roman Empire by the Christian culture, which was especially manifested in the calendar struggle.

2 The notion of a "civilized society" is used here in the sense of the anthropological determination "advanced or literate or mainly urban society" [18] 
For example, in the late Roman Empire, on December 25 people celebrated the birth of the deity of Mitra, as some theoreticians claim [25] or a holiday dedicated to the Sun, "Natalis Solis Invicti," as others claim [26]. During the time of strengthening and expansion of Christianity, since no exact date of Christ's birth existed, the Church decided to adopt December 25 as the date of Christ's birth [27]. Thus, the newly converted into Christianity could celebrate Christ's birth on the same date when Mitra's or solar birth was once celebrated. This is just one of many cases where one culture suppresses gradually the other ones by using the calendar as a collective memory bearer.

Parallel use of two or more dating systems is a natural consequence of the co-existence of two or more cultures within society. For example, a Greek historian, Diodorus of Sicily, as a loyal Roman citizen dates event according to Roman consuls in his work "Bibliotheca Historica," but as an admirer of Greek classics, first of all of Athens traditions, he also dates events according to Athenian archons and Olympic Games [28]. Thus, the co-existence and creolization of two calendars could be seen as a new type of culture, which follows its own rules, but also recognize its origin. However, since culture diffusion is a continuous process, at a certain point creolized forms lose such properties because of their assimilation.

The Revised Julian calendar is an example of the modification and partial assimilation of the Julian calendar into the Gregorian calendar to diminish the disharmony between the East and West, i.e. between the Julian and Gregorian calendars. Whereas a majority of Orthodox Churches have adopted the new calendar, those from Serbia, Russia and Jerusalem have not [29], most likely due to the resistance to novelties from the West. For instance, a Serbian theologian Justin Popović regarded the new calendar "as dangerous non-Orthodox innovations" [30].

A modern example of resistance and conflict between cultures is also the conflict on the territory of the former Yugoslavia, where, due to the civil wars in the Nineties, the religious and cultural space was strictly divided and where on the calendar basis all adaptation and diffusion processes were stopped. In the former Yugoslavia, the Gregorian calendar was in official use and many secular holidays were introduced, which, due to intensive administrative support, drew out some traditional calendar holidays based on the religious and cultural heritage. If one carefully examines the calendars from that time, it can be noticed that one or two religious holidays in this unified calendar had the significance of a state holiday, but without any formal administrative support (namely, holidays were celebrated, but they were working days) [31]. After the disintegration of Yugoslavia, numerous religious calendar holidays, which had been drawn out earlier, were included in the secular calendars - Eastern Christian holidays in Serbia, the Republika Srpska, Montenegro and Macedonia, Muslim holidays in the Federation of Bosnia and Herzegovina and Kosovo, and Western Christian ones in Croatia and Slovenia. In this way, a calendar has become a basis of a cultural, social and political divisions.

These examples are a result of gradually formed calendars through the process of cultural interaction. Therefore, the calendar is the most universal characteristic and form of cultural self-evaluation. It produces essential cultural elements such as the idea of time, the idea of proper identity, origin, and action. Also, it confirms the self-identity of a given culture and its distinction from other cultures. A parallel existence of two calendars means a gradual creolisation of cultures, whereas the calendar "competition" means a conflict between the two cultures.

\section{Attempt on Culture Shift based on Calendar}

Calendar reform is any significant revision of a calendar system. It presupposes the transition from one calendar system to another one. Although a prevailing opinion is that most reforms are aimed at synchronizing a calendar to the astronomical year as closely as possible [9], history 
shows that some calendar reforms were without any advantages concerning the accuracy of time determination compared to the predecessor. Examples include the French Republican Reform from the 18th century [32] and the Soviet Revolution Reform from the 20th century [33]. Their purpose was, in the first place, to destroy the preceding culture through the abolishment of old holidays and the introduction of new ones. In this way, the new culture, directly through the calendar (i.e., adopting a list of completely new holidays which had nothing to do with the tradition), opposed to all contemporaneous and earlier cultures. The republic and monarchy could not socially reconcile so that their space-time co-existence became impossible. However, these calendars were not used for long, not because of being insufficiently exact, but because culture, i.e. collective memory, could not be introduced artificially and by force. For instance, the adoption of a ten-day working week in France instead of the traditional one lasting seven days was especially unpopular. The same was true for the five-day working week in the USSR.

The modern calendar reform attempts are tendencies towards the creation of a planetary universal calendar. The following question is posed: can these attempts be regarded as supracultural, purely scientific projects, where the determinations of both day duration and year duration do not depend on social institutions and cultural phenomena similar to them?

Supposing for a moment that, due to the increasing influence of western civilization, January 1 st and the year AD 1 are the day and the year of the origin of the whole world, what would the contents of the annual calendar look like? What criterion, understandable and acceptable to everybody, could be introduced to position a year day? Since the duration of a day and a year are determined based on the natural order of things ("laws of nature") and thus have a universal character, the simple ordinal numeration of year days seems objective and supracultural! However, does the annual cycle then describe the basic categories of culture, similar to the western one, but to a significant extent withdrawn from its historical fundament? If it does, does it then satisfy that similar culture?

Unfortunately, there is no substantial support for the attempts of conventional unification on the basis of goodwill and scientific justification of the highest order. For instance, in 1957, India adopted the national Indian calendar, based on a scientific approach and proposed by a group of competent astronomers and astrophysicists [34]. However, the wider community rejected its use and still ignores, for instance, the New Year's Day in favor of other holidays.

The conclusion is that the unification of time calculation in the calendar systems represents a form of the world culture unification. Any displacement towards such unification involves the abolishment of the calendar as a culture criterion and its coalescence with culture as a whole. The unification is, however, desirable only for one part of humanity, whereas it is probably non-realistic, perhaps impossible for the entire humanity.

\section{Conclusion}

At the beginning of the paper, the notion of a calendar was introduced as a link between the cosmos and mankind, and it is considered as an instrument in creating and studying culture. Even though it is recognized as an element of culture in literature, the main focus is usually on the culture of specific social communities such as, for example, Old-American and African civilizations and social groups. Therefore, the paper considers and compares several calendar systems and shows that the calendar is indeed a criterion for the recognition and formation of culture in general.

In the paper, the calendar is used as a new criterion in defining culture and it is accepted as a specific form of a collective memory of human societies. The role of these societies in establishing a cosmological model through the category of time is seen as a culture generator and instrument for its 
transformation.

The presented examples of cultural interaction show that a calendar is a changeable sociological category of cosmological importance. Depending on the type of cultural interaction, the calendar is usually a) in the state of constant development (a more complex form of survival); b) in the state of reorganization (a simpler form of survival); or c) in the process of abolishment. Therefore, the calendar (as a parameter for culture determination) could be accepted, modified or rejected.

The paper argues that the purpose of calendar reform is not only to bring the calendar into accordance with the astronomical year, but also to organize time units to meet the actual necessities of the society. According to this preliminary analysis, it seems that it is almost impossible to achieve a world consensus about the directions of culture development and the introduction of its universalities in the collective world memory as long as the current diversity levels of the present calendar systems persist. These systems are mostly historical, but they also have indicative and normative powers similar to the power of a state.

The paper concludes that the calendar with both time conceptions, the cyclical and the linear, is a structurally organized system that serves the purpose of planning and preserving the cycle of secular and spiritual events (i.e., non-calendar and calendar holidays). In this sense, a calendar appears as a basis for characterizing a social community and the condition of its general and special survival.

\section{References}

1. Fischer, M. Culture and Cultural Analysis as Experimental Systems. Cultural Anthropology 2007, 22.

2. Kroeber, A.; Kluckhon, C. Culture: A Critical Review of Concepts and Definitions. Papers of the Peabody Museum of American Archaeology and Ethnology 1954, 47, 149.

3. Chanchani, S.; Paul, T. Typologies of Culture. University of Otago, Department of Accountancy and Business Law Working Papers 2002, 4, 3.

4. Tyler, E. Primitive Culture: Researches into the development of Mythology, Phylosophy, Religion, Art, and Custom; John Murray: London, 1871; p. 1.

5. Kirchhoff, P. Mesoamerica, sus limites geogrficos, composicion etnica y caracteres culturales. Suplemento De La Revista Tlatoani 1960, 3, 13.

6. Kroeber, A. Anthropology. Race, Language, Culture, Psychology. Prehistory; Harcourt, Brace: New York, 1948; p. 787.

7. Bartle, P. Forty Days: The Akan Calendar. Journal of the International African Institute 1978, 48, 80 - 84 .

8. Konadu, K. The Calendrical Factor in Akan History. International Journal of African Historical Studies 2012, 45 .

9. Doggett, L. Calendars. In Explanatory Supplement to the Astronomical Almanac; Seidelmann, K., Ed.; University Science Books: California, 1992; pp. 575 - 609.

10. The murder of the Austrian Crown Prince. 1914-06-15. http://istorijskenovine.unilib.rs/view/index.htmlissue:NLS_00007_19140615 (Collection of the University Library "Svetozar Markovic") [In Serbian].

11. The murder of the Austrian Crown Prince and his wife. Illustrirtes Wiener Extrablatt 1914-06-29. http:/ / anno.onb.ac.at/cgi-content/annoshow?call=ext | 19140629 | 1 | 33.0 | 0 (Collection of the National Library of Austria) [In German].

12. Parker, R. The Calendars of Ancient Egypt. In Studies in Ancient Oriental Civilization; Allen, T., Ed.; The University of Chicago Press: Chicago, 1950; p. 38.

13. Ovid. Fasti (J. G. Fraser, Trans.). In Leob Classical Library (Vol. 253); Goold, G., Ed.; Harvard University Press: Cambridge, MA, 1931; p. 38.

14. of Caesarea, E. Preparation for the Gospel (Vol. 3) (E. H. Gifford, Trans.; R. Pearse, Ed.). https:/ / tinyurl.com/r6vn82t. 
15. Kuzenkov, P. How old is the world. The Byzantine Era and its rivals. In Proceedings of the 21st International Congress of Byzantine Studies; E. Jeffreys, F. Harrer, J.G., Ed.; Ashgate: Hampshire, 2006; pp. 21 - 26.

16. Islamic Calendar. In The Oxford Dictionary of Islam; Esposito, J., Ed.; Oxford University Press: New York: Oxford, 2003; p. 145.

17. Boyce, M. Zoroastrians: Their Religious Beliefs and Practices; Routledge: London, 2001; p. 104.

18. Kroeber, A. Style and Civilizations; Cornell University Press: Ithaka, NY, 1957; p. 150.

19. Park, G. Animism. In Encyclopaedia Britannica Online; 2018.

20. Wilkinson, E. Chinese History: A Manaul; Harvard University Asia Center: Cambridge, MA, 2000; p. 181.

21. Lendering, J. Varronian Chronology, 2008. http://www.livius.org/articles/concept/varronian-chronology/.

22. Eidinow, E. Olympiad. In The Oxford Classical Dictionary; S. Hornblower, A. Spawforth, E.E., Ed.; Oxford University Press: Oxford: New York, 2012; p. 1037.

23. Redfield, R.; Linton, R.; Herskovits, M. Memorandum for the Study of Acculturation. American Anthropology 1936, 38, $149-150$.

24. Chattopadhyaya, P. Environment, Evolution and Values; Concept Publishing Company: New Delhi, 2007; p. 126.

25. Vermaseren, M.; Essen, C.V. he Excavations in the Mithraeum of the Church of Santa Prisca in Rome; Brill: Leiden, 1965; p. 238.

26. Beck, R. Merkelbach's Mithras. Phoenix 1987, 41, 299.

27. Roll, S. Toward the Origins of Christmas; Kok Pharos Publishing House: The Netherlands, 1995; pp. 127 134.

28. Walbank, F. Sources for the Period. In The Cambridge Ancient History (1st ed., Vol. 7); Walbank, F., Ed.; Cambridge University Press, 1984; p. 6.

29. M. Dimitrijević, E. Theodossiou, E.; Mantarakis, P. Milutin Milanković and the Reform of the Julian Calendar in 1923. Journal of Astronomical History and Heritage 2016, 41, 53.

30. Louth, A. Modern Orthodox Thinkers: From the Philokalia to the Present; InterVarsity Press: Illinois, 2015; p. 146.

31. Statistical calendars of Yugoslavia; Savezni Zavod za statistiku: Belgrade, 1961 - 1988. (In Serbian).

32. Munro, A. French Republican Calendar. In Encyclopaedia Britannica Online. http:/ / www.britannica.com/science/French-republican-calendar.

33. Soviet calendar. In The book of calendars; Parise, F., Ed.; Facts on File: New York, 1982; p. 377.

34. Chatterjee, S. Indian Calendric System; Publications Division, Ministry of Information and Broadcasting, Government of India, 1998. 